\title{
Importance of Porch in Mediterranean Architecture
}

\author{
Turgay Salihoğlu ${ }^{1}$
}

\begin{abstract}
With the Industrial Revolution, human beings have faced ecological problems. For this reason, the term "Sustainable Architecture" came up in the architectural field. In 1987 the United Nations Environmental Commission redefined this term. Also in 1992, the United Nations Conference on Environment and Development in Rio de Janeiro, Brazil the human being adopted some principles. When we look at the principles of "Sustainable Architecture", we can briefly refer to these principles as "Natural Climatization" or "Thermal Comfort". In spite of all this process, many architects still produce projects under the name of a "Modern Architecture" without considering the culture of life formed by climatic conditions in this process. Because of this, most of the users lost their confidence in "Modern Architecture". This is not "Sustainable Architecture". However, the housing built in the past in the rural areas and urban, and even the official buildings are an open laboratory. When the laboratory in Cyprus is examined we can say that, "the Porch Planned" type houses, which is developed by the experiments in the Rural Area Housings during the period, started to build also in the cities. We see this development, arising from the climatic conditions, in the Government Agency buildings and Bureaucrats and Military Officers' houses that has built by the British Rule which commands the Cyprus Island during 1878-1960. In addition, porch-planned houses are also seen in the houses that C.M.C (Cyprus Mines Coorparation), which started its activities in 1914 due to the rich copper deposits in the Lefke region, built for its employees.
\end{abstract}

Keywords: Environment. Solar Radiations. Sustainable Architecture. Thermal Comfort. Porch.

\section{Introduction}

Sustainability is a term that arises to better convey the nature to future generations and not to harm nature, ecological balance and society. (Kidd,1992) This term is defined by the United Nations Environment Assembly in 1987 as "Humanity has the ability to sustain the development without endangering the ability to respond the requirement and by providing the daily needs of the next generations"(Bruntland (ed), 1987). Also in 1992, at the United Nations Conference on Environment and Development in Rio de Janeiro, Brazil, it was accepted that "the human beings are at the center of the phenomenon of Sustainable Development, and that every human being has the right to a healthy and productive life in harmony with nature" (Earth Summit, 1992).

When we look at the principles of "Sustainable Architecture", we see that it is, minimizing the energy consumption and being compatible with the place where materials are made (https://www.un.org). In short, we can call it "Natural Climatization" or "Thermal Comfort".

Thermal comfort is a design function that should be kept the thermal comfort of the people, animals and even machines using the volumes, within the recommended normal values. The concept of thermal comfort is not only related to heat values as is known, along with the temperature, radiant heat, humidity, air circulation speed, metabolic temperature, it also includes atmospheric events such as the heat dissipated by human or 
machines which are used the volume. The intention here is that, increase and decrease in air temperature, and naturally affects the thermal control in the same direction. In the case of high heat capacity of the material used in the building, the energy, absorbed from the heat or solar radiation is then reflected in thermal heat as the temperature. Relative humidity causes the real temperature to feel higher or lower.

As devices such as refrigerators, washing machines and vacuum cleaners, which are integral parts of modern life, operate with electrical energy, the energy input of these devices is reflected as an increase in temperature in their living space. (Salihoğlu, 2018, Givoni,1998)

\section{Porch-Planned Type in Rural Areas}

When we look to Cyprus Island in general, it is observed that in the regions where dry farming exist, especially in the Central Mesarya region, rural area houses are built in the courtyard system. In residential areas where there is no dry farming, rural area houses are generally built in without a courtyard system. In the mass settlement of the land, an effort was made to take the most advantage of the prevailing wind in the summer months.

In closed spaces, openings (door-windows) on the exterior facade are kept extremely small. The windows and doors are arranged to allow the wind to easily go through the closed space.

In addition, continuous efforts have been made to protect and benefit from the solar radiation and as a result "the porch" is built on the living space that serve the purpose.

The courtyard in the housings with the courtyard system, is the most important element of the living space, where the housewives do their daily work, the children's playground and the reception area for the guests. These actions, within the porch arrangement, move into the porch are when the courtyard is affected by solar radiation excessively or when the air temperature is not too low, but on rainy days.

In addition to these, with the opening of the double leaf swing door to the South or West, the solar radiation was utilized in the winter. However, in summer, the interior of indoor spaces could not be protected from the direct effect of solar radiation. For this reason, the porch is arranged in front of the living rooms in order to be more protected and to benefit from solar radiation (Salihoğlu,2006).

Due to the solar radiation in Cyprus came with an angle of $77^{\circ}$ in summer and $35.1^{\circ}$ in winter season, living spaces benefited from solar radiation mostly in winter. On the other hand, in the summer season, living spaces are protected from the direct effect of solar radiation (Salihoğlu,2006).

The porch was used mostly in areas where there was no dry farming, in other words, in areas where there was little dust and fodder particles brought by the prevailing wind during the summer months. Although dry and irrigated farming is carried out together in Karpaz region and despite the small amount of dust and fodder particles that come along with the prevailing winds, we can say that especially the summer months in these regions, all life has been passed on the porch. (Figure 1 


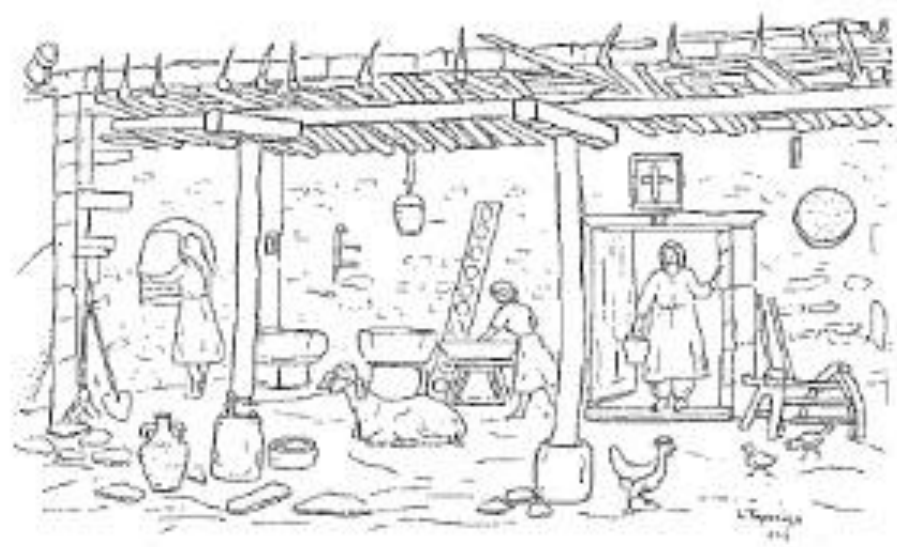

Figure1: A porch view from the Dipkarpaz village. (From A.Tassuly, 1963)

Then, in some regions, the arch is built from the cut natural stone which is called a yellow stone (sandstone or buri stone) in colloquial speech, to the porch where the great majority of life is passed. The main reason for this is that there is not enough wood in some parts of Cyprus and also there is not enough wood preservative materials. Thus, plunk timber bays and beams are removed. In addition, visuality is provided by making motifs on various parts of the arch columns (Salihoğlu,2006). In the process, "Plan type with porch" started to build in large urban suburbs and in small cities especially. (Figure 2).

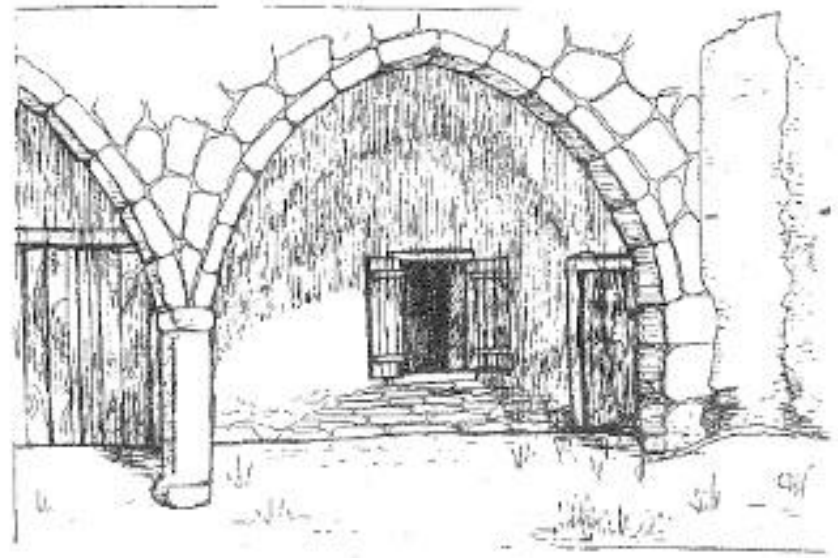

Figure2: View of arched porch. (From T.Salihoğlu, 2006)

\section{British Governining Period}

Although the Cyprus island was a British dominion in between 1878-1960, the housing architecture of the Cypriot culture in general did not change. Demolishing buildings that partake of ancient arts were restored without endamaging its original. And 
in order to get the planning permission for the new buildings, it was stipulated by the legislated law that historical values should be taken into account. (Schaar et al, 1995, Salihoğlu,2006) In addition, we see that importance is given to natural climatization in the official buildings as well as in the houses of bureaucrats and military officers. In addition, buildings were constructed using local materials. Because local materials are the most suitable material for climatic conditions.

\subsection{Governmental Buildings}

As an example of governmental (agency) buildings, today we can show the building used and known as "Court House" the capital city Nicosia. This building was designed by the architect Charles Bellamy as a Neoclassical architectural style and was constructed between 1900-1904 on the Sarayönü Square in Nicosia. Neoclassical architecture emphasizes walls instead of light shadow play as a form, and prefer to give a separate architectural identity to each wall area. This building was used as land office, post office and commissariat . (www.mahkemeler.net, April 2019)

The offices are lined up side by side and the porches are in front of the office rooms. As in the traditional houses of Cyprus, the roofs of the main building and the porch were built on different levels. (Schaar et al., 1995) The ground floor porch is arched and the top floor porch is made of wood. Sandstone is used as building material. Local building materials are the most suitable building materials for natural climatization. The building made using sandstone (yellow stone in colloquial speech) is compatible with the Physical Environment of the city that formed within the process. (Picture1,2)

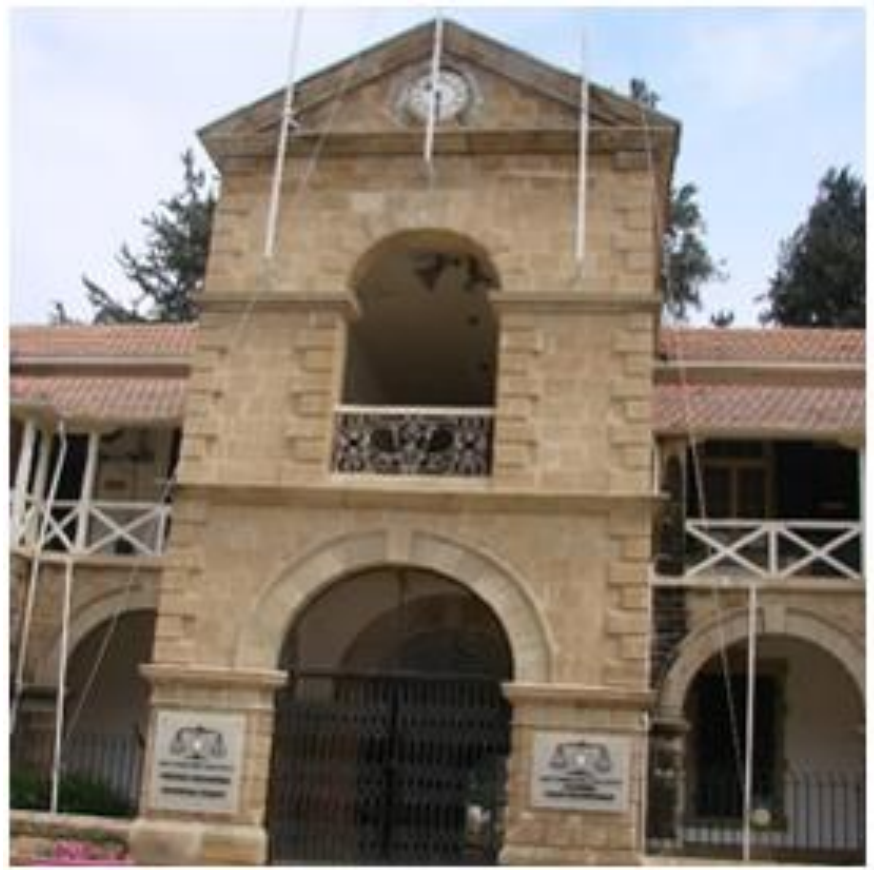

Picture 1:View of the main entrance gate of the courts building. (by T.Saliboğlu) 


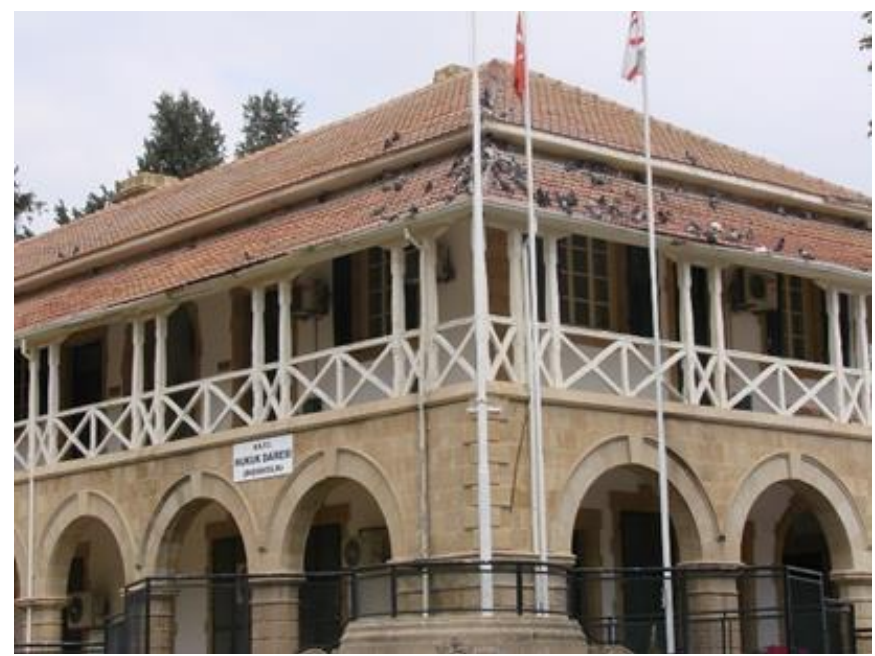

Picture2: View of the building of the current courts. (by T.Saliboğlu)

As an annex to the main rectangular building on the south east, a group of buildings were planned in a way that they formed an inner courtyard (Figure 3)

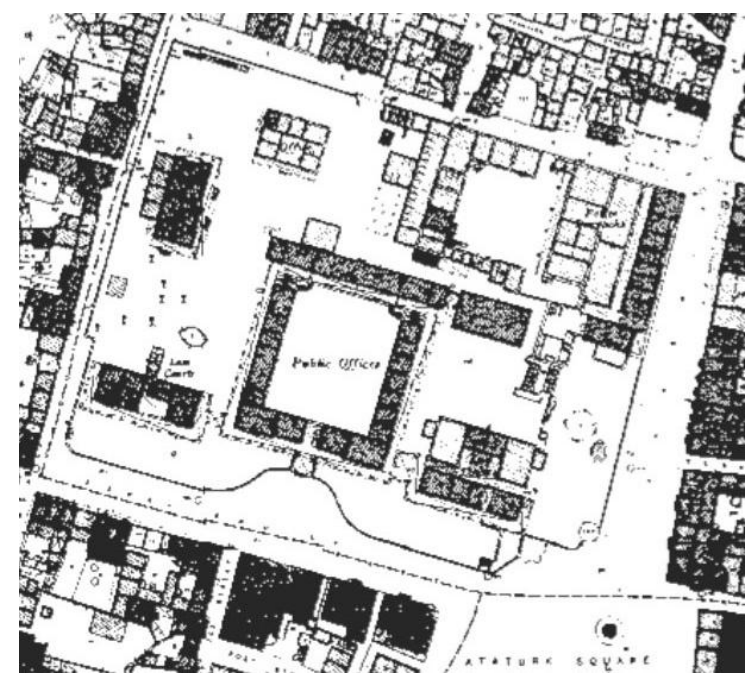

Figure 3: Map of the current building of courts. (Courtesy of TRNC mup office, 2019)

The inner courtyard is one of the most important elements of natural climatization in continental climates. "The Central Mesarye Region" of Cyprus island has a Continental climate within the Mediterranean climate. The city of Nicosia is located in this region.

\subsection{Bureaucrat and Military Officer Houses.}

The housings for the senior bureaucrats and military officers are exist at the present time. And when these are examined, it is seen that the they were built in the neoclassical architectural style as in the government agency buildings which were used as 
the court buildings.

In these houses, porch is built in the living areas and bedrooms. However, in these houses, as in official offices, the porch and main building roofs are not at different levels. Figure 4)
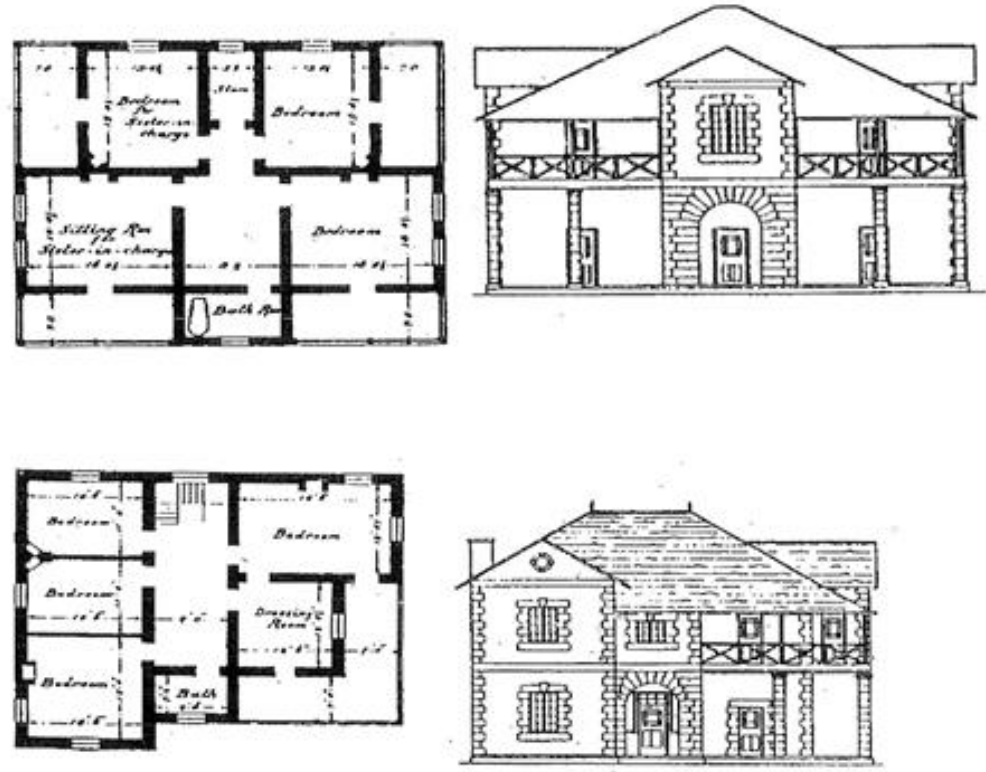

Figure 4: Plan and front views of bureaucrats and military officers' houses. (Schaar,K,W et.al 1995)

\section{City of Lefke Mine Houses.}

The American-based mining company C.M.C (Cyprus Mines Coorparation), which started its activities in 1914 due to the rich copper deposits in the Lefke region, has built about 500 houses in the region for its employees. (www. Lefkebelediyesi.com) The housings are located in the two separate regions of the city of Lefke, Xero and Karadağ. The construction dates of the houses, made in three stages, are 1922, 1926 and 1928. The status and marital status of the employees were taken into consideration when the houses were built. For this reason they are built as, single worker houses, married worker houses, foreman houses and engineer houses. (www. Lefkebelediyesi.com)

\subsection{Houses of Single Workers.}

The houses were built as single-roome, common porch and adjacent to each other (figure 5). The toilets are located in the courtyard, one for the two-three houses. The areas of these houses vary between 0.32 and $0.34 \mathrm{~m}^{2}$. There is sleeping and kitchen are in a single room. The kitchen sink was also used for bathing purposes because there was no bath in the house. There were no floor covering on the floor and the outer walls were painted white on the concrete plaster up to the foundation. The only color in the buildings is the red color used in wooden windows and doors. 


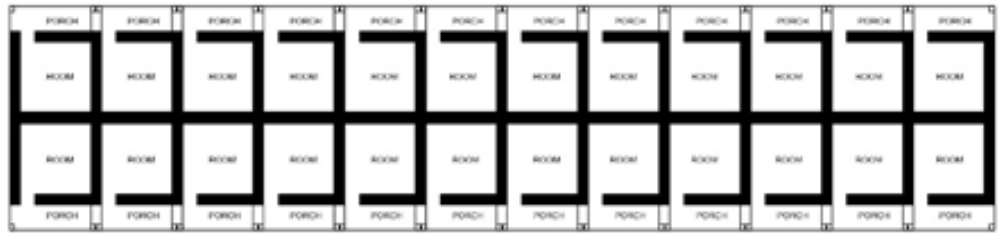

Figure 5: Single worker house block and single room plan. (Adapted from C.Beyaz, 2017)

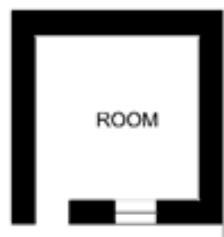

PORCH

\subsection{Houses of the Married Worker}

The houses with two bedrooms, a kitchen and a living room were built adjacent as in single workers' houses. The houses are porched. Each house has its own toilets in the courtyard. The areas of the houses vary between $0.40-0.50 \mathrm{~m}^{2}$. (Figure 6) Kitchen doors were designed from horizontal split half wood. While the lower part of the door was closed, the upper part could be used as a window for the ventilation of the kitchen.
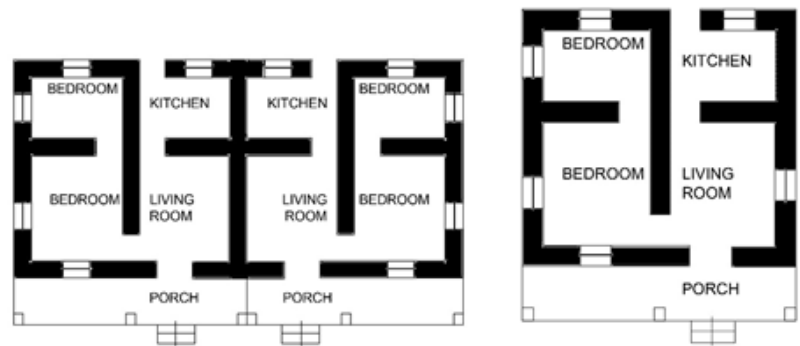

Figure 6: Married worker houses block and single room plan. (Adapted from C.Beyaz, 2017)

\subsection{Foreman Houses}

In these houses, which have two bedrooms and a kitchen, the toilet is located in the courtyard as in the workers' homes. There is also a single room for bathroom use in the courtyard.

There was no porch as in the worker's houses. It is understood that the small porch on the entrance frontage is built only for protecting the living room and the second bedroom doors from the direct effects of solar radiation and the rain.

On the other hand, the most easily obtained materials are used according to climatic conditions. These materials are red fire brick walls and adobe materials on the stone foundation. (Figure 7)

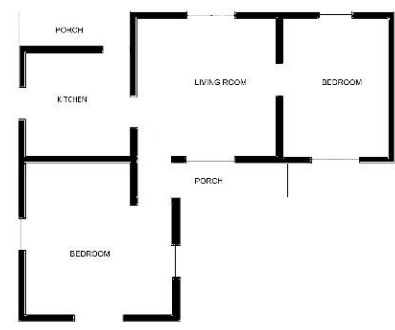

Figure 7: Foreman house plan. (Adapted from C.Beyaz, 2017) 


\subsection{Engineer Houses}

Engineer houses were built in two separate areas, such as other housings. However, the plan types in these houses differ according to the regions. The houses are single storey and consist of three bedrooms, living room, bathroom, toilet and kitchen. The areas of these houses vary between $80.4-106.6 \mathrm{~m}^{2}$.

The houses built in the Karadağ region, are designed through the view in order to not to block each other. Red fire brick was used as a wall material in the houses. (Figure 8-9) The porch is not used in these houses. However, when we examine the city of Lefke as in the rural and urban suburbs, we see the entrance hall type of plan. The entrance halls were a place where all life passes. In general, as the doors were opening opposing in the entrance halls, air circulation was provided and natural climatization was acquired. Especially when the plan of figure 9 is examined, we see the same case.

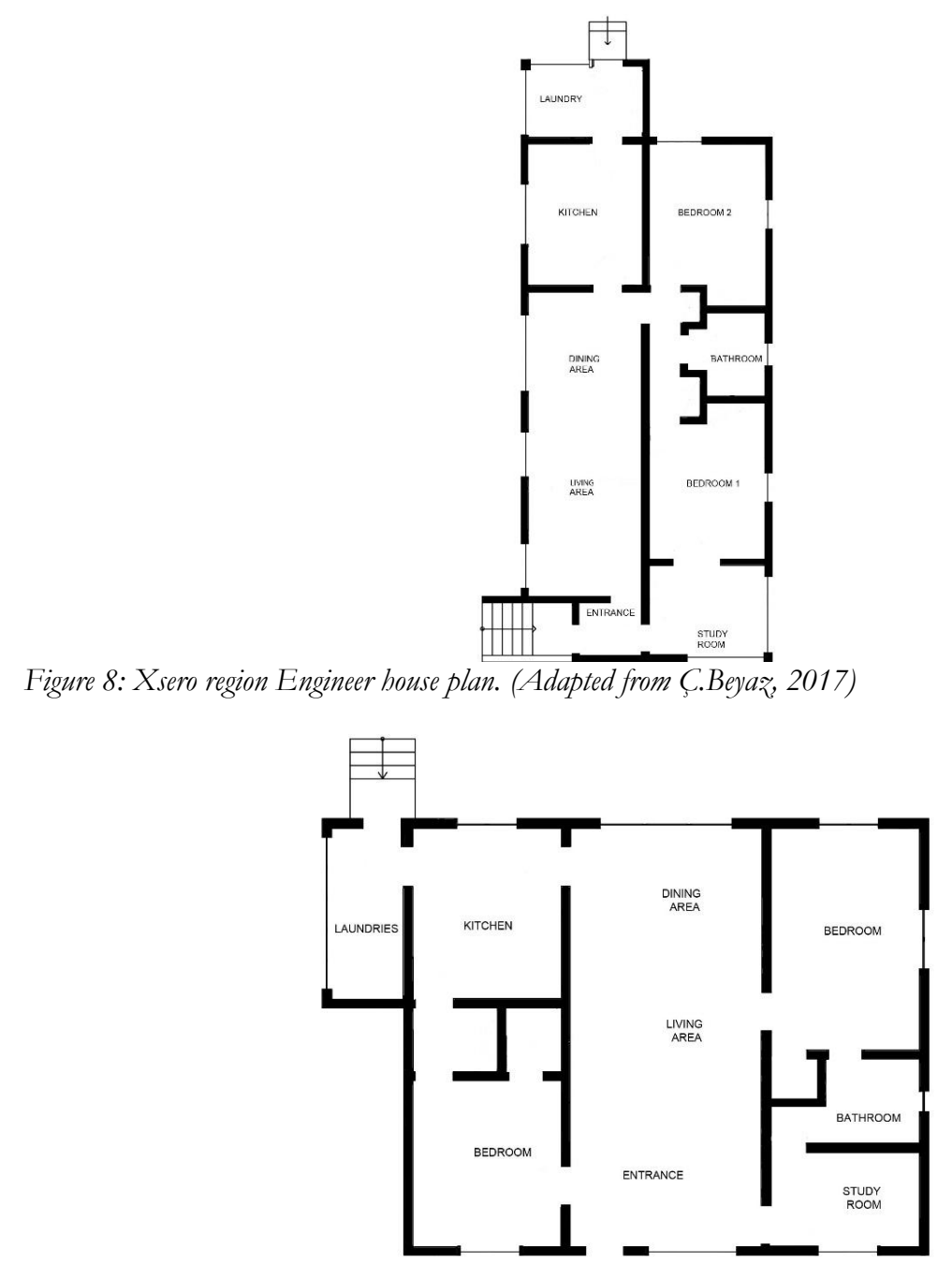

Figure 9: Karadağ region Engineer house plan. (Adapted from C.Beyaz, 2017) 
On top of above mentioned porches, its interesting to notice that even the auxiliary houses constructed in the Montenegrin region were planed and constructed with porch (Picture 3).

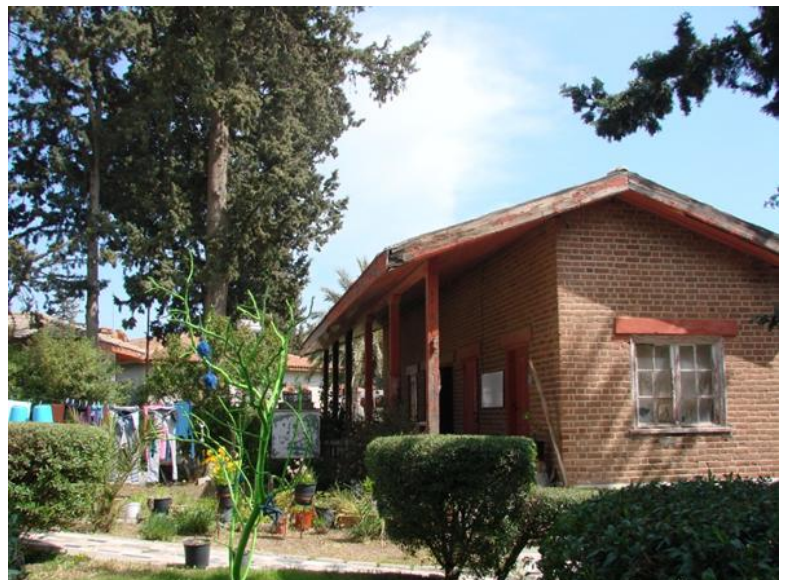

Picture 3. Vievw of an auxilary house (by T.Saliboglu)

\section{Conclusion}

Before designing a project, the architect analyzes the life culture of the user arising from the climatic features. Then, meteorological data of the area where the building is located are gathered, the orientation is given importance and the functional space layout is arranged and as a result, the project to be implemented is obtained.

However, today, some architects produce a project under the name of "Modern Architecture", without considering the culture of life. Thus, in addition to the Natural Environment, we are faced with housings incompatible with the Physical Environment which occur within the process. In addition to the damage to the environment in general, the users are also losing their confidence in Modern Architecture. This is not a sustainable architecture.

\section{Reference}

[1] Kidd CV (1992) The evolution of sustainability. J Agr Environ Ethic 5(1):1-26

[2] Bruntland G (ed), 1987, Our common future: the world commission on environment and development, Oxford University Press

[3] United Nations Conference on Environment and Development (UNCED), Earth Summit, Agenda 21, Rio de Janeiro, Brazil, 3-14 June 1992

[4] United Nations (UN) Sustainable Development (2019)

https://www.un.org/sustainabledevelopment/sustainable-consumption-production/

[5] Givoni,B. (1998) 1987, Climate considerations In Bulilding And Urban design,New York 1998, pp:3

[6] Salihoğlu,T. (2018) Thermal comfort in traditional house architecture within the Mesarya Region of the island of Cyprus, The Turkish Online Journal of Design Art and Communication, Volume8, Issuez2, 2018, pp:394

[7] Salihoğlu,T. (2006) Kıbrıs Adasında Konut, Dörtrenk Matbaacılık LTD, Lefkoşa,2006, pp:220,236,273

[8] Tassuly,A, Cyprus I,II, Nicosia, 1963 
[9] Schaar,K.W, et al. (1995) Under The Clock. Colonial Archicture And History İn Cyprus 1878-1960, Nicosia, 1995, pp22-24

[10] www.mahkemeler.net

[11] Courtesy of TRNC mup office.

[12] www. Lefkebelediyesi.com

[13] Beyaz, Ç, et al, Gradual Transformation of CMC Houses in Lefke within the Context of Housing Transformation, Article (PDF Available). June 2017 with 226 ReadsDOI: 10.7596/taksad.v6i3.917 